\title{
CARACTERÍSTICAS DE PRODUÇÃO DO CAPIM-BUFFEL SUBMETIDO A INTENSIDADES E FREQÜÊNCIAS DE CORTE\#
}

\author{
CHARACTERISTICS OF PRODUCTION OF BUFFEL GRASS AS FUNCTION \\ OF CUTTING INTENSITY AND FREQUENCY
}

\author{
Edvan, R.L. ${ }^{1 *}$, Santos, E.M. ${ }^{2 A}$, Da Silva, D.S. ${ }^{2 B}$, De Andrade, A.P. ${ }^{2}$, Costa, R.G. ${ }^{2}$ \\ e Vasconcelos, W.A. ${ }^{3}$
}

\begin{abstract}
${ }^{1}$ Universidade Federal do Ceará. Fortaleza, CE. Brasil. *agroloiola@hotmail.com
2Universidade Federal da Paraíba. Departamento de Zootecnia. Areia-PB. Brasil. Aedson@cca.ufpb.br; Bdivan@cca.ufpb.br

${ }^{3}$ Instituto Nacional do Semiárido. Campina Grande, PB. Brasil.
\end{abstract}

\section{Palavras chave adicionais}

Características estruturais. Manejo de pastagem. Semiárido.

\section{RESUMO}

Objetivou-se avaliar características morfogênicas, estruturais e a produção de biomassa do capim-buffel sob intensidades e freqüências de corte. Utilizou-se um pasto já implantado de capimbuffel, cultivar Molopo. A área total utilizada foi dividida em 20 parcelas de $8 \mathrm{~m}^{2}$ cada com linha de bordadura de $1 \mathrm{~m}$ entre as parcelas. Foi utilizado um esquema de parcelas subdivididas no tempo, tendo nas parcelas um arranjo fatorial $2 \times 2$ referente a combinações entre duas alturas de corte $(60$ e $80 \mathrm{~cm})$ e duas alturas de resíduo $(20$ e $40 \mathrm{~cm})$, em delineamento experimental de blocos completos ao acaso, com cinco repetições, totalizando 20 unidades experimentais, que receberam as denominações 20-60, 20-80, 40-60, 40-80. Houve efeito $(p<0,05)$ dos tratamentos para a produção de matéria seca por corte, sendo que os tratamentos 20-80 e 40-80 resultaram em maiores produções. O perfilhamento, relação lâmina/colmo, número de folhas vivas por perfilho e diâmetro de touceira, foram influenciados $(p<0,05)$ pelas diferentes formas de manejar o pasto de capimbuffel. A taxa de aparecimento de folhas e o filocrono não diferiram $(p>0,05)$, entre os tratamentos. A freqüência e a intensidade de corte

\#Parte da dissertação de mestrado do primeiro autor, financiada pelo Instituto Nacional do Semiárido.

Recibido: 8-10-09. Aceptado: 8-6-11.

\section{ADDITIONAL KEYWORDS}

Structural characteristics. Pasture management. Semi arid.

influenciaram o perfilhamento, relação lâmina/colmo e a produção de matéria seca do capim-buffel tanto para o corte como para a produção total.

\section{SUMMARY}

The objective of this experiment was to evaluate morphogenetic and structural characteristics and biomass production of buffel grass as a function of cut intensities and frequencies. A previously established pasture of buffel grass cultivar Molopo was used. Total area was splited in twenty $8 \mathrm{~m}^{2}$ experimental unities with $1 \mathrm{~m}$ border lines. A split plot scheme was used with plot in factorial scheme $2 \times 2$ to combination of two height of cut $(60$ and $80 \mathrm{~cm})$ and two height post cut $(20$ and $40 \mathrm{~cm}$ ). The experimental design was entirely randomized blocks, with five replicates named 20 $60,20-80,40-60,40-80$. There $(p<0.05)$ of treatments for dry matter per cut production and higher values were observed to $20-80$ and $40-80$. Tillering, leaf/steam ratio, number of alive leafs per tiller and diameter of plant were influenced by $(p<0.05)$ by different management of buffel grass. Leaf appearance ratio and phylocron were not different $(p>0.05)$ between treatments. Cutting frequency and intensities influenced tillering, leaf/ stem ratio and dry matter production for both the cut as to the total.

Arch. Zootec. 60 (232): 1281-1289. 2011. 


\section{INTRODUÇÃO}

O semiárido brasileiro pode ser definido como uma região com regime pluviométrico baixo e irregular, com $350 \mathrm{~mm}$ a $800 \mathrm{~mm}$ de precipitação anual, composto principalmente por vegetação predominante tipo xerófila. Vegetação essa adaptada ao clima seco da região, podendo resistir a períodos prolongados de secas, que são comuns no local e ocorrem ciclicamente, trazendo prejuízos à produção pecuária.

Segundo revisão feita por Menezes e Sampaio (2002), inúmeros dados mostram e dão suporte às afirmações gerais sobre a vocação pecuária da região semiárida do nordeste brasileiro e explicam o insucesso da atividade agrícola com culturas herbáceas anuais não adaptadas ao estresse hídrico.

O capim-buffel é uma espécie perene, de crescimento vertical variando de 0,6 a $1,5 \mathrm{~m}$ de altura, dependendo da variedade ou cultivar (Neto et al., 2000). Como opção forrageira para regiões semiáridas, o capimbuffel que é originário da África, Índia e Indonésia, e foi introduzido no Brasil em 1952, no Estado de São Paulo, de onde foi transferida para o nordeste e após passar por algumas avaliações iniciais, demonstrou possuir características consideradas importantes para região, como adaptabilidade a regimes pluviométricos até mesmo inferiores a $500 \mathrm{~mm}$ e exigência média a fertilidade de solos (Oliveira, 1993).

Ainda neste contexto, Neto et al.(2000), estudando o efeito da precipitação e do corte no capim-buffel, observaram que o rendimento de matéria seca do capim aumenta com a aplicação de água, até o nível de precipitação de $373 \mathrm{~mm}$, em todas as idades ao primeiro corte. Demonstrando que o capim-buffel responde bem as regiões com níveis de precipitações baixos.

Os mecanismos morfofisiológicos que regem o crescimento das plantas forrageiras e de sua interação com o ambiente são importantes para compreender a capacidade produtiva da pastagem (Hodgson, 1990) Segundo Da Silva e Nascimento Junior (2007), o conhecimento das variáveis estruturais e da morfogênese das plantas forrageiras é uma importante ferramenta para a determinação das condições do pasto (altura, massa de forragem, massa de laminas foliar e índice de área foliar) adequadas para assegurar produção animal eficiente e sustentável em áreas de pastagem. No caso específico do capim-buffel são escassas na literatura informações sobre a dinâmica de crescimento dessa gramínea após o corte e/ ou pastejo.

Devido às características ecofisiológicas do capim-buffel, práticas de manejo baseadas em conceitos de características morfogênicas, características estruturais e acúmulo de forragem no pasto, são importantes para estabelecer manejo adequado para essa gramínea nas regiões semiárida do Brasil.

Dessa forma, este estudo foi conduzido com objetivo de avaliar características morfogênicas, estruturais e acúmulo de biomassa do capim-buffel sob intensidades e freqüências de corte.

\section{MATERIAL E MÉTODOS}

O experimento foi realizado na Estação Experimental do Instituto Nacional do Semiárido, localizada no município de Campina Grande, Paraíba. Sendo utilizada uma pastagem de capim-bufel (Cenchrus ciliaris cv. Molopo) já implantada há dois anos. Antes do início do experimento foram coletadas amostras de solo da camada 0-20 $\mathrm{cm}$ de profundidade, que apresentou a seguinte composição química e de matéria orgânica: $\mathrm{pH}=6,3 ; \mathrm{P}=14 \mathrm{mg} / \mathrm{kg} ; \mathrm{K}=80 \mathrm{mg} /$ $\mathrm{kg} ; \mathrm{H}=1,63 \mathrm{cmolc} / \mathrm{kg} ; \mathrm{Al}=0,05 \mathrm{cmolc} / \mathrm{kg}$; $\mathrm{Ca}=1,37 \mathrm{cmolc} / \mathrm{kg} ; \mathrm{Mg}=0,77 \mathrm{cmolc} / \mathrm{kg} ; \mathrm{MO}=$ $19 \mathrm{~g} / \mathrm{kg}$. Com base neste resultado não foi necessário fazer a correção da acidez. Foi realizado adubação mineral, utilizado a seguinte formulação N-P-K: 40-10-40, sendo utilizado $200 \mathrm{~kg}$ da mistura por hectare, 


\section{PERFILHAMENTO E PRODUÇÃO DO CAPIM-BUFFEL SUBMETIDO A CORTE}

utilizando como fontes o sulfato de amônia, o superfosfato simples e o cloreto de potássio respectivamente.

A área total utilizada foi dividida em 20 parcelas de $8 \mathrm{~m}^{2}$ cada com linha de bordadura de $1 \mathrm{~m}$ entre as parcelas. Foi utilizado um esquema de parcelas subdivididas no tempo, tendo nas parcelas um arranjo fatorial $2 \times 2$ referente a combinações entre duas alturas da planta no momento do corte $(60$ e $80 \mathrm{~cm})$ e duas alturas de resíduo $(20$ e $40 \mathrm{~cm})$, em delineamento experimental de blocos completos ao acaso, com cinco repetições, totalizando 20 unidades experimentais, que receberam as seguintes codificações: 20-60 (altura de resíduo de $20 \mathrm{~cm}$ combinada com altura de corte de $60 \mathrm{~cm}$ ); 20-80 (altura de resíduo de $20 \mathrm{~cm}$ combinada com altura de corte de $80 \mathrm{~cm}$ ); 40-60 (altura de resíduo de $40 \mathrm{~cm}$ combinada com altura de corte de 60 $\mathrm{cm}$ ) e 40-80 (altura de resíduo de $40 \mathrm{~cm}$ combinada com altura de corte de $80 \mathrm{~cm}$ ).

O experimento foi realizado na estação chuvosa (tabela I) em 171 dias, de fevereiro a julho e foi conduzido até o limite do estabelecimento da gramínea no campo e até que cada tratamento atingisse sua altura de corte. Cada tratamento teve um período experimental e intervalo de corte diferente. Nos tratamentos 20-60, 20-80, 40-60 e 40-80 foram realizados $3,3,5$ e 4 cortes com duração de 144, 153, 146 e 170 dias, respectivamente.

A altura do pasto foi medida utilizandose uma régua de aço de $2 \mathrm{~m}$ de comprimento graduada em centímetros. Sendo tomadas leituras em quatro pontos aleatórios por unidade experimental. A altura de cada ponto correspondeu à altura média do plano de folhas em torno da régua. Para monitorar a altura de resíduo, utilizaram-se quadrados de madeira confeccionados nas duas alturas pré-estabelecidas, que serviu de base para o corte com máquina segadora costal.

Para a avaliação de perfilhamento foram utilizadas duas touceiras por unidade experimental de $8 \mathrm{~m}^{2}$ de área, utilizando-se cinco repetições por tratamento. Estas foram selecionadas em pontos onde a altura representa a condição média da parcelas no momento da marcação das plantas. Os perfilhos foram contados e marcados com arames revestidos de plástico de cor determinada. A cada nova amostragem, realizada sempre na condição de pós-corte, novos perfilhos foram marcados com cores diferentes. Dessa forma, foi possível estimar a população de perfilhos após cada corte. Nas mesmas touceiras foram mensuradas as características morfogênicas, sendo determinadas em dois perfilhos basais por tratamento com arames revestidos de plástico de cor específica, avaliando os perfilhos a cada sete dias, durante todo experimento. A cada corte foram escolhidos outros dois perfilhos basais para as avaliações posteriores do número total de folhas, números de folhas expandidas, número de folhas em expansão, número de folhas mortas, que permitiu calcular a taxa de aparecimento de folhas (TApF), o número de folhas vivas por

Tabela I. Médias mensais, climáticas registrada na estação meteorológica do Instituto Nacional do Semiárido, durante os meses do experimento. (Climatic variables taken in the meteorological station of Instituto Nacional do Semiárido).

\begin{tabular}{lccccc}
\hline Variáveis climáticas & Fevereiro & Março & Abril & Maio & Junho \\
\hline Precipitação mm & 0,7 & 407,3 & 56,9 & 83,4 & 47,5 \\
Temperatura $^{\circ} \mathrm{C}$ & 27,6 & 26,3 & 24,6 & 23,9 & 22,3 \\
Nebulosidade* $^{*}$ & 7,1 & 6,9 & 7,9 & 8,2 & 7,9 \\
\hline
\end{tabular}

*Escala de 1-10: 10 representa a nebulosidade máxima. 
perfilho (NFVP) e o filocrono (intervalo de dias entre o aparecimento de duas folhas sucessivas). Ao final de cada corte nestas touceiras, foi avaliado o perímetro utilizando uma fita métrica para obtenção do diâmetro de touceira.

Para a determinação da massa seca de forragem produzida e da composição morfológica foram colhidas amostras representativas acima da altura de resíduo estabelecida para cada tratamento. A forragem colhida na área de $8 \mathrm{~m}^{2}$ de cada parcela foi pesada, coletando-se amostra de aproximadamente $200 \mathrm{~g}$ que foi pré-seca em estufa de ventilação forçada a $65^{\circ} \mathrm{C}$, até atingir peso constante, para posterior determinação do teor de matéria seca (MS).

Amostras de forragem foram separadas manualmente nas frações lâmina foliares e colmo (colmo + bainhas foliares), as quais foram pesadas e secas em estufa de circulação forçada de ar a $65^{\circ} \mathrm{C}$ até atingir peso constante, objetivando-se determinar o teor de MS do pasto. A determinação dos componentes morfológicos foi realizado durante todo o período experimental. Os valores de massa de forragem foram convertidos para $\mathrm{kg} / \mathrm{ha}$ de MS e os componentes morfológicos expressos como percentagem (\%) da massa de forragem.

Os dados foram submetidos à análise de variância e as médias foram comparadas pelo teste de Tukey, adotando-se um nível de significância de 5\%. Os dados foram analisados utilizando-se o procedimento GLM do pacote estatístico SAS (SAS Institute, 1993).

\section{RESULTADOSEDISCUSSÃO}

Conforme a tabela II pode-se observar que houve efeito $(\mathrm{p}<0,05)$ dos tratamentos para a produção de matéria seca por corte. Sendo que os tratamentos com resíduo 20 $\mathrm{cm}$ e altura de corte $80 \mathrm{~cm}(20-80)$ e o tratamento com resíduo $40 \mathrm{~cm}$ e altura de corte $80 \mathrm{~cm}$ (40-80) obteve maior produção. Esse fato é explicado porque os tratamentos em que o pasto foi cortado a uma altura de $80 \mathrm{~cm}$ independente da altura de resíduo, possibilitaram um maior tempo para acumular biomassa.

Para a produção de matéria seca total houve diferença $(\mathrm{p}<0,05)$ para os tratamentos, sendo que o de resíduo $20 \mathrm{~cm} \mathrm{e}$ altura de corte $60 \mathrm{~cm}(20-60)$, foi o que obteve menor valor de produção. Isso sugere que o corte com resíduo $20 \mathrm{~cm}$ foi severo, e provavelmente as plantas levaram mais tempo para se recuperar, e, conseqüentemente o tratamento $20-60$ foi o que apresentou menor valor de produção de biomassa, possivelmente esse corte promoveu a retirada do meristema apical do perfilho, já que o capim em questão tem crescimento cespitoso. Estudo feito por (Matthew et al., 2000) ressalta que a altura de corte é importante, pois afeta a velocidade de rebrote, em razão da quantidade de tecido foliar fotossintetizante remanescente após o corte ou pastejo. Dessa forma a fase inicial da rebrota é lenta até que um número suficiente de folhas tenha se expandido e passe a contribuir substancialmente para a foto-

Tabela II. Valores médios e respectivos coeficientes de variação (CV\%) da produção de matéria seca por corte (PMSC) e produção de matéria seca total (PMST) submetido à diferente altura de resíduos e de corte. (Average values and coefficient of variation of dry matter production per harvest (PMSC) and dry matter production (PMST) as a function of intensities and cutting frequencies).

\begin{tabular}{lcc}
\hline Tratamento & PMSC t/ha & PMST t/ha \\
\hline $20-60$ & $0,37^{\mathrm{b}}$ & $1,12^{\mathrm{b}}$ \\
$20-80$ & $0,84^{\mathrm{a}}$ & $2,54^{\mathrm{a}}$ \\
$40-60$ & $0,49^{\mathrm{b}}$ & $2,41^{\mathrm{a}}$ \\
$40-80$ & $0,79^{\mathrm{a}}$ & $3,14^{\mathrm{a}}$ \\
CV (\%) & 25,50 & 21,40 \\
\hline
\end{tabular}

Médias seguidas de letras diferentes nas colunas diferem entre si $(p<0,05)$. 


\section{PERFILHAMENTO E PRODUÇÃO DO CAPIM-BUFFEL SUBMETIDO A CORTE}

ssíntese da cultura (Nabinger, 1997). Ainda neste contexto segundo Sbrissia e Da Silva (2001), o balanço de carbono (C) negativo causado pela respiração só se tornará positivo quando a massa surgida for capaz de assimilar C suficiente par superar as perdas por senescência e respiração. Os outros tratamentos não diferiram $(\mathrm{p}>0,05)$ entre si para a produção de matéria seca total. Porém o tratamento 20-80 apesar de elevada produção, diferentemente do tratamento 20 60 , propiciou às plantas mais tempo para acumular uma maior quantidade de fitomassa e se recuperar do corte residual baixo, não obstante, essa biomassa apresentasse baixa relação lamina/colmo (tabela III).

Pode-se ainda observar uma elevada produção de fitomassa para o tratamento com resíduo $40 \mathrm{~cm}$ e altura de corte $80 \mathrm{~cm}$, embora não tenha sido estatisticamente superior aos tratamentos 20-80 e 40-60. Isso se deve provavelmente à freqüência de cortes observada nesse tratamento, apesar de ter sofrido um corte a menos que o tratamento 40-60. Segundo Gomide (1997), essa variável do manejo interage com características morfológicas da planta, como altura média do meristema apical e número de gemas basilares, para determinar a recuperação de gramíneas cespitosas após o corte. Dessa forma se observa que não é necessário um corte de resíduo baixo para ter uma elevada produção, pois, corte com resíduo mais alto, pode resultar em elevadas produções além de permitir que as plantas tenham provavelmente um melhor valor nutritivo da biomassa acumulada, já que resulta em maior acúmulo de folhas.

De acordo com a figura 1, observa-se a influência do tempo sobre a produção de fitomassa, com aumento da produção ao longo do período experimental, esse fato esta relacionado com a precipitação pluviométrica e ao estimulo do corte. A produção de matéria seca de uma espécie é dependente da sua adaptação aos fatores de meio e do manejo aplicado (Cavalcanti Filho et al., 2008).

Para o tratamento 40-60 ainda observase um declínio de produção no último corte, esse fato se deve porque esse período corresponde ao final do período chuvoso além das baixas temperaturas (tabela I), lembrando que este tratamento se estendeu mais que os outros. Dessa forma, à época do ano e o corte promovem a abertura do dossel possibilitando a entrada de luz solar, fato que reconhecidamente promove a diferenciação das gemas axilares que dão origem a novos perfilhos (Matthew et al., 2000),

Tabela III. Valores médios e respectivos coeficientes de variação (CV\%) da relação lâmina/ colmo $(L / C)$, número de perfilhos (NP), taxa de aparecimento de folhas (TApF), número de folhas vivas por perfilho (NFVP), filocrono e diâmetro da touceira (DT cm) submetido à diferente altura de resíduo e corte. (Average values and coefficient of variation for leaf/steam ratio (L/C), number of tillers (NP), number of green leaves per tiller (NFVP), leaves appearance rate (TApF), phyllocron and diameter of shoots (DT $\mathrm{cm}$ ) as a function of intensities and cutting frequencies).

\begin{tabular}{ccccccc}
\hline Tratamento & L/C & NP & NFVP & TApF folhas/dia & Filocrono & DT cm \\
\hline $20-60$ & $0,93^{\mathrm{b}}$ & $28,77^{\mathrm{c}}$ & $4,56^{\mathrm{b}}$ & 0,22 & 3,28 & $23,25^{\mathrm{c}}$ \\
$20-80$ & $1,08^{\mathrm{b}}$ & $49,10^{\mathrm{b}}$ & $6,90^{\mathrm{a}}$ & 0,22 & 4,66 & $37,10^{\mathrm{b}}$ \\
$40-60$ & $1,67^{\mathrm{a}}$ & $57,50^{\mathrm{a}}$ & $6,90^{\mathrm{a}}$ & 0,27 & 4,28 & $40,26^{\mathrm{a}}$ \\
$40-80$ & $1,39^{\mathrm{ab}}$ & $65,50^{\mathrm{a}}$ & $6,80^{\mathrm{a}}$ & 0,25 & 4,15 & $33,82^{\mathrm{b}}$ \\
CV $(\%)$ & 18,64 & 17,83 & 8,60 & 24,37 & 21,16 & 6,85 \\
\hline
\end{tabular}

Médias seguidas de letras diferentes nas colunas diferem entre si $(p<0,05)$. 
EDVAN, SANTOS, DA SILVA, DE ANDRADE, COSTA EVASCONCELOS
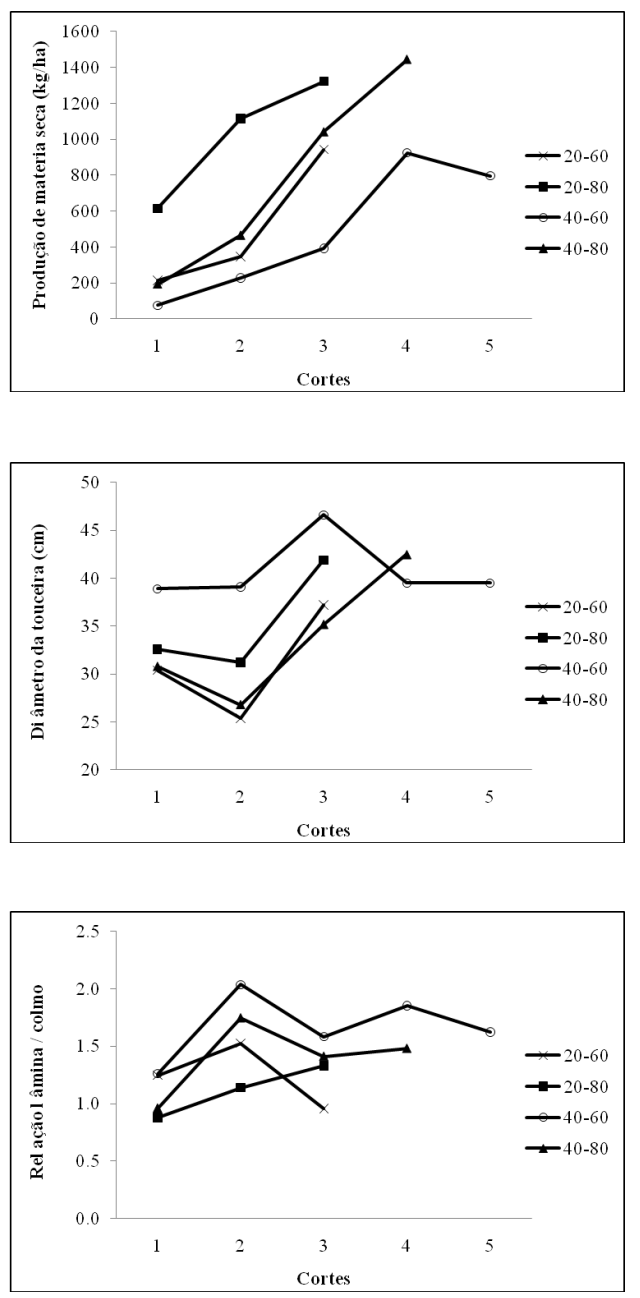

Figura 1. Produção de matéria seca, diâmetro de touceira e relação lâmina/colmo em relação aos cortes de cada tratamento: resíduo de $20 \mathrm{~cm}$ e altura de corte $60 \mathrm{~cm}(20-$ 60); resíduo de $20 \mathrm{~cm}$ e altura de corte de 80 cm (20-80); resíduo de $40 \mathrm{~cm}$ e altura de corte de $60 \mathrm{~cm}(40-60)$ e resíduo de $40 \mathrm{~cm}$ e altura de corte $80 \mathrm{~cm}(40-80)$. (Dry matter production, stump diameter and leaf/stem in relation to cuttings by treatment: residue of $20 \mathrm{~cm}$ and $\mathrm{cm}$ height at $60(20-60)$, residue of $20 \mathrm{~cm}$ and cutting height at $80 \mathrm{~cm}(20-80)$; residue of $40 \mathrm{~cm}$ and cutting height at $60 \mathrm{~cm}(40-60)$ and residue of 40 $\mathrm{cm}$ and cutting height at $80 \mathrm{~cm}(40-80)$ ). notadamente perfilhos basilares, aumentado assim a produção de matéria seca.

Operfilhamento foi influenciado $(\mathrm{p}<0,05)$ pelas as diferentes formas de manejar o pasto de capim-buffel (tabela III), sendo que os tratamentos com corte residual de 40 $\mathrm{cm}$ apresentaram maior população de perfilhos em comparação com o corte residual de $20 \mathrm{~cm}$. Segundo Matthew et al. (1999) o processo de perfilhamento nas gramíneas é de grande importância para a produção forrageira e o manejo tem papel crucial, uma vez que as taxas de aparecimento e mortalidade de perfilhos resultam em mudanças na dinâmica da população de perfilhos e produtividade do pasto durante $\mathrm{o}$ ano. $\mathrm{O}$ maior número de perfilhos do tratamento 40-80 pode ser explicado pela altura de resíduo, onde altura de resíduo 40 $\mathrm{cm}$ parece estimular o perfilhamento no capim-buffel, já que em contrapartida os tratamentos com resíduo $20 \mathrm{~cm}$ apresentaram menores quantidades de perfilhos. Estudo feito por Santos et al. (2001) mostra características morfológicas e de perfilhamento em plantas de capim-elefante sob quatro alturas de corte em duas épocas do ano, concluindo que os cortes mais elevados resultaram em plantas mais altas independente da época do ano e tiveram proporções maiores de folhas e maior número de perfilhos aéreos. Provavelmente o tratamento 40-80 teve um grande número de perfilhos aéreos já que houve uma maior incidência de iluminação nesta altura do dossel.

O fato dos tratamentos com resíduos de $40 \mathrm{~cm}$ terem resultado em um maior número de cortes também pode ter influenciado o aparecimento de perfilhos. Esse fato ocorre devido à plasticidade da planta em relação ao manejo. Sendo caracterizado pelo estudo de Lemaire (2001), onde relata que a planta tem uma amplitude de resposta plástica em relação à escala de tempo que dispõem para adaptar-se a mudança no ambiente. Dessa formas as plantas forrageiras que são submetidas às diferentes condições e 


\section{PERFILHAMENTO E PRODUÇÃO DO CAPIM-BUFFEL SUBMETIDO A CORTE}

intensidade de desfolhação em pastagens, procuram se adaptar, assegurando assim sua perenidade e eficiência fotossintética.

Referente à relação lâmina/colmo houve efeito $(\mathrm{p}<0,05)$ dos tratamentos, onde o 4060 apresentou uma maior relação que 20-60 e 20-80. Provavelmente esse fato ocorreu devido à altura de resíduo ter sido de $40 \mathrm{~cm}$ e a de corte $60 \mathrm{~cm}$, estrato no qual o capim apresenta uma levada produção de folhas. O tempo também influenciou esse tratamento que apresentou um maior número de cortes, não havendo, provavelmente, tempo suficiente para a gramínea se desenvolver, e, no caso os perfilhos não se alongarem, se mantendo pequenos mais em grande quantidade. Em contrapartida o tratamento 20-60 obteve menor relação lâmina/colmo mais não diferiu $(\mathrm{p}>0,05)$ dos tratamentos 20-80 e 40-80. No 20-60 também é possível perceber menor número de perfilhos, tendo então perfilhos longos, demonstrando o efeito do manejo no desenvolvimento do capim-buffel.

Para o número de folhas vivas por perfilho observou-se diferença $(p<0,05)$, sendo que os tratamentos 20-80, 40-60 e 4080 não diferiram $(p>0,05)$ entre si. Esse fato pode ser comprovado pelo fato do número de folhas por perfilho ser uma característica genética pouco influenciada pelos fatores abióticos. Somente o tratamento com resíduo $20 \mathrm{~cm}$ e altura de corte $60 \mathrm{~cm}$ teve o menor valor de número de folhas por perfilhos, devido ao manejo conduzido neste tratamento.

A taxa de aparecimento de folhas e o

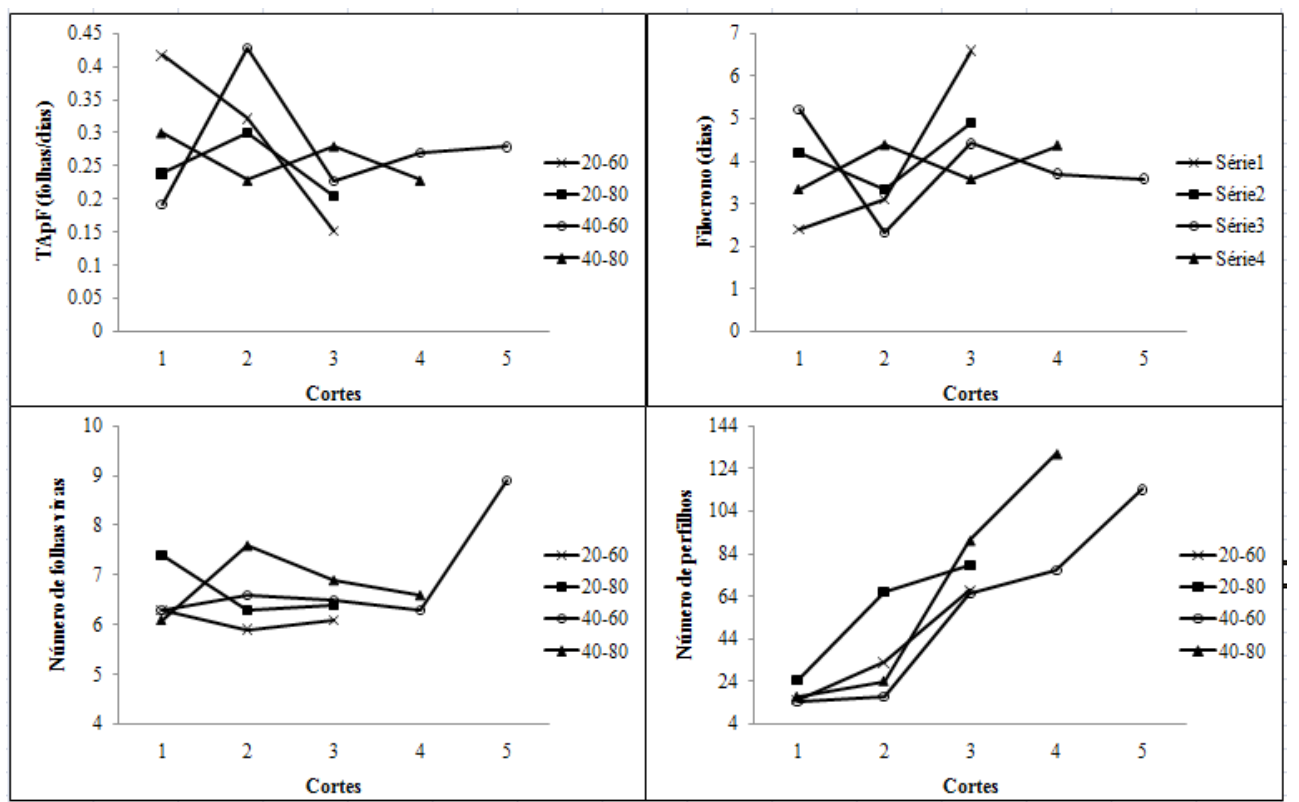

Figura 2. Taxa de aparecimento de folhas, filocrono, número de folhas por perfilhos e número de perfilhos em relação aos cortes de cada tratamento: resíduo de $20 \mathrm{~cm}$ e altura de corte $60 \mathrm{~cm}$ (20-60); resíduo de $20 \mathrm{~cm}$ e altura de corte de $80 \mathrm{~cm}$ (20-80); resíduo de $40 \mathrm{~cm}$ e altura de corte de $60 \mathrm{~cm}$ (40-60) e resíduo de $40 \mathrm{~cm}$ e altura de corte $80 \mathrm{~cm}$ (40-80). (Leaves appearance rate (TApF), phyllocron, number of green leaves per tiller (NFVP) and number of tillers (NP) in relation to each treatment: residue of $20 \mathrm{~cm}$ and cutting height at $60 \mathrm{~cm}(20-60)$, residue of $20 \mathrm{~cm}$ and cutting height at $80 \mathrm{~cm}(20-80)$; residue of $40 \mathrm{~cm}$ and cutting height at $60 \mathrm{~cm}(40-60)$ and residue of 40 $\mathrm{cm}$ and cutting height at $80 \mathrm{~cm}(40-80))$. 
filocrono não diferiram ( $p>0,05)$, entre os tratamentos, não obstante o filocrono esteja diretamente influenciado pela taxa de aparecimento de folhas já que é o inverso da taxa de aparecimento de folhas. Por isso não se observou efeito $(p>0,05)$. De acordo com Rezende et al. (2008), o corte favorece o aparecimento de perfilho como também a taxa de aparecimento de folhas. Apesar do tratamento 40-60 ter apresentado um grande número de cortes não foi o suficiente para aumentar a taxa de aparecimento de folhas (figura2).

Para variável diâmetro de touceira houve efeito $(p<0,05)$ para as diferentes formas de se manejar o capim-buffel. O que se observa é que o tratamento com resíduo $40 \mathrm{~cm} \mathrm{e}$ altura de corte $60 \mathrm{~cm}$ obteve o maior $(\mathrm{p}<0,05)$ diâmetro de touceira. Esse fato ocorreu, provavelmente, porque esse tratamento era manejado com maior freqüência, forçando assim a touceira de capim a aumentar o seu diâmetro, já que os cortes eram mais freqüentes que nos outros tratamentos. Esse fato ocorre devido à plasticidade fenotípica do capim-buffel em relação ao manejo empregado. Conforme pode ser observado na figura 1, os tratamentos 20-80 e 40-80 obtiveram formação de touceira semelhantes ao longo dos cortes e o 20-60 obteve o menor diâmetro de touceira fato que pode ser explicado devido ao menor número de perfilho (figura2).

\section{BIBLIOGRAFIA}

Cavalcanti Filho, L.F.M., Santos, M.V.F., Ferreira, M.A., Lira, M.A., Modesto, E.C., Dubeux Jr., J.C.B., Ferreira, R.L.C. e Silva, M.J. 2008. Caracterização de pastagem de Brachiaria decumbens na zona da mata de Pernambuco. Arch. Zootec., 57: 391-402.

Da Silva, S.C. e Nascimento Junior, D. 2007. Avanços na pesquisa com plantas forrageiras tropicais em pastagens: características morfosiológicas e manejo do pastejo. Rev. Bras. Zootecn., 36: 121-138.

Gomide, J.A. 1997. Morfogênese e análise de crescimento de gramíneas tropicais. Simpósio
O capim-buffel cultivar Molopo por ser uma planta cespitosa de porte médio-alto parece apresentar maior produção de matéria seca total quando manejado com altura de resíduo de $40 \mathrm{~cm}$, além de proporcionar um maior número de perfilho e uma alta relação lâmina/colmo. O alto índice de perfilhamento confere a gramínea uma maior persistência no pasto, fato importante na região semiárida. Sendo assim o manejo adequado já que proporciona um melhor desempenho da forrageira e uma maior produção por área. A altura de corte de $80 \mathrm{~cm}$ resultou em maior produção de matéria seca por corte. Em pastagem de capim-buffel como em outras gramíneas saber a altura de corte é importante para se realizar um manejo correto, pois proporciona um melhor desempenho da forrageira, além de ser uma forma prática de manejar o pasto.

\section{CONCLUSÕES}

A freqüência e a intensidade de corte influenciaram o perfilhamento, relação lâmina/colmo e a produção de matéria seca do capim-buffel tanto para o corte como para a produção total.

O capim-buffel cultivar Molopo quando manejado utilizando altura de resíduo de 40 $\mathrm{cm}$ apresenta maior produção de matéria seca total, maior população de perfilhos e boa relação lâmina/colmo.

Internacional sobre a Produção Animal em Pastejo. Universidade Federal de Viçosa. Anais... Viçosa, MG. pp. 411-445.

Hodgson, J. 1990. Grazing management: Science into practice. John Wiley e Sons. New York. 203 pp.

Lemaire, G. 2001. Ecophysiology of grasslands: Dynamic aspects of forage plant populations in grazed swards. International Grassland Congress, $19^{\circ}$. Proceedings... Piracicaba. Fundação de Estudos Agrários "Luiz de Queiroz". Piracicaba. pp. 29-38.

Matthew, C., Yang, J.Z. and Potter, J.F. 1999. 


\section{PERFILHAMENTO E PRODUÇÃO DO CAPIM-BUFFEL SUBMETIDO A CORTE}

Determination of tiller and root appearance in perennial ryegrass (Lolium perenne) swards by observation of the tiller axis, and potential application to mechanistic modeling. New Zeal. Grassland Association, 50: 1-10.

Matthew, C., Assuero, S.G., Black, C.K., Da Fonseca, D.M., Mosquim, P.R. and Gobbi, K.F. 2000. Tiller dynamics of grazed swards. In: Lemaire, G. et al. (eds.). Grassland ecophysiology and grazing ecology. CABI Publishing. Wallingford. pp. 127-150.

Menezes, R.S.C. e Sampaio, E.V.S.B. 2002. Simulação dos fluxos e balanços de fósforo em uma unidade de produção agrícola familiar no semi-árido paraibano. Em: Silveira, L.M., P. Petersen, E. Sabourin. (Org.). Agricultura familiar e agroecologia no semi-árido: avanços a partir do Agreste da Paraíba. AS-PTA. Rio de Janeiro. pp. 249-260.

Nabinger, C. 1997. Eficiência do uso de pastagens: Disponibilidade e perdas de forragem. Em: Peixoto, A.M. et al. (eds.). Simposio sobre manejo da pastagem: fundamentos do pastejo rotacionado, 14. Anais... FEALQ. Piracicaba. pp. 213-251.

Neto, J.D., Santos, F.A.S., Furtado, D.A. e Matos,
J.A. de 2000. Influência da precipitação e idade da planta na produção e composição química do capim-buffel. Pesqui. Agropecu. Bras., 35: 1867-1874.

Oliveira, M.C. 1993. Capim-buffel: produção e manejo nas regiões secas do Nordeste. EmbrapaCPATSA. Petrolina. (Circular Técnica, 27). 18 $\mathrm{pp}$.

Rezende, C.P., Pereira, J.M., Pinto, J.C., Muniz, J.A., Borges, A.M.F., Andrade, I.F. e Evangelista, A. 2008. Dinâmica de perfilhamento e fluxo de biomassa em capim-cameroon sob lotação rotativa. Rev. Bras. Zootecn., 37: 1750-1757.

Santos, E.A., Silva, D.S. e Queiroz Filho, J.L. 2001 Perfilhamento e algumas características morfológicas do capim-elefante cv. Roxo, sob quatro alturas de corte nas duas épocas do ano. Rev. Bras. Zootecn., 30: 26-32.

SAS Institute. 1993. SAS/STAT. User's guide statistics. v. 6. $4^{\text {a }}$ ed. Cary. USA.

Sbrissia, A.F. e Silva, S.C. da. 2001. O ecossistema de pastagens e a produção animal. Sociedade Brasileira de Zootecnia (Org.). A produção animal na visão dos brasileiros. Fundação de Estudos Agrários Luiz de Queiroz. Piracicaba, SP. pp. 731-754. 